\title{
GROSS MOTOR SKILLS AND PHYSICAL ACTIVITY LEVEL: IS THERE ANY GENDER DIFFERENCES IN NINE YEARS OLD CHILDREN?
}

\author{
Aleksandra Aleksic Veljkovic ${ }^{1}$, Nenad Stojiljkovic ${ }^{1}$, Lucija Milcic ${ }^{2}$ \\ ${ }^{1}$ Faculty of Sport and Physical education, University of Nis, Serbia \\ ${ }^{2}$ Faculty of Kinesiology, University of Zagreb, Croatia
}

\begin{abstract}
Proper growth and development of young school children require mastering different skills, especially gross motor skills - basic locomotor and manipulative skills. It is essential to monitor the physical activity of nine-year-old children necessary for further proper development and healthy habits, which will continue into adulthood. This study aims to determine physical activity level, BMI, and gender differences in the performance of gross motor skills in children aged nine years $( \pm$ six months). The study involved 40 participants (20 girls and 20 boys). Their body height, body weight, and body mass index were $140.46 \pm 5.72 \mathrm{~cm} ; 37.84 \pm 8.21 \mathrm{~cm}$; and $19.09 \pm 3.56$, respectively. All participants completed the Physical Activity Questionnaire for Children and performed the Test of Gross Motor Development, Second Edition (TGMD-2), and two sub-tests of BOT-2 (Speed and Agility and Upper-Limb Coordination). T-test for independent samples was used to compare groups according to physical activity level (physically active and inactive group) and explore interactions with gender and BMI, and gross motor skills variables. F-values, $p$-values, and partial eta squared $\left(\eta^{2}\right)$ values were reported as MANOVA outcomes. The results showed a significant difference between physical activity level and locomotor skills but not in manipulative skills. Further research should focus on various exercise programs that contribute to developing skills and participation in organized physical activity of children of different ages.
\end{abstract}

Keywords: locomotor skills, manipulative skills, physical education, physical activity

\section{THEORETICAL BACKGROUND}

Regular physical activity is of great importance for the proper growth and development of children, their psycho-physical progress, and cognitive abilities (FLORIANI - KENNEDY, 2008). Adequate childhood activity can be an essential determinant of health in adulthood, as there are numerous risk factors associated with inadequate physical activity in childhood (HILLS et al., 2011). The main factors that threaten the physical fitness of children are: insufficient amount of movement and decreased physical activity, inadequate nutrition, both in volume and quality and other harmful habits (GAO et al., 2018). Physical activity in children has a favorable effect on the psycho-physical level, which includes the development of health, the development of muscle strength and physical endurance, improving the flexibility and coordination of movement, and mental development (PATKI et al., 2015). Research has shown that preschool and primary school children's physical activity is not at an adequate level (HILLS et al., 2011; LANDRY - DRISCOLL, 2012). 
The development of gross motor skills can be defined simply as the acquisition of control and large muscle groups of the body. These skills are also known as "basic motor skills." Fundamental motor skills include body movement (locomotor skills), body manipulation (non-motor actions), and object manipulation or ball-handling skills (WILLIAMS - ABERNATHY, 2004). Basic locomotor skills are walking, running, hopping, and jumping. A lot of the research is dedicated to understanding and accurately assessing the development of basic motor skills, and knowledge in this field should help professionals find the right way to work effectively in motor skills with young children (ANDRIYANI, 2014). When a child learns to walk, run, climb, jump, and throw, the adopted movements are aligned and used to adopt more complex habits such as catching, hitting the ball, reeling, riding tricycles, bicycles, roller skates, skiing, skating, and swimming.

Manipulative skills are basic motor skills that involve the use and manipulation of various objects (balls, sticks, hoops...). The timely and proper acquisition of fundamental motor skills enables perceptual, cognitive, and affective processes in children. Manipulative skills include top and bottom throwing, rolling, shooting, headbanging, kicking, panting, and catching (DERRI et al., 2001). They may consist of the upper (arms or head) or lower extremities and can also be transmitted by force to an object to move away from the body or to place some part of the body in front of an approaching object to turn or stop it (CHEN et al., 2016). They also depend on the children's abilities, the rules of the game or activity, the level of skill development, etc. These skills are necessary for intentional and controlled interaction with facilities and the environment and successful participation in various activities and sports (DERRI et al., 2001). Failure to start early in the development of manipulative skills reflects a failure in motoring during childhood and adolescence (GALLAHUE - DONNELLY, 2003) due to shame for poor performance, fear of injury, or difficulty learning the whole movement.

Much research has investigated the development of motor skills in school-age children (CAMERON et al., 2016; ERICSSON - KARLSSON, 2014). Most of the studies do not examine variations in the motor skills of typically developed children, and most often, data have been collected to detect motor behavior deficits (COOLS et al., 2009). The tests used for assessment must have good metric characteristics and norms for the age being tested (LOPES et al., 2018; WAGNER et al., 2015; WAGNER et al., 2017). The previous study showed that the performance of four to six-year-old children in tasks which involved gross motor skill did not relate with BMI (CATENASSI et al., 2007).

Proper growth and development of young school children require mastering gross motor skills. Besides, it is vital to monitor children's physical activity at this age, as it is necessary for further, proper, and undisturbed development, as well as for the acquisition of healthy habits. This study aims to determine the physical activity level, BMI, and gender differences in the gross motor skills of nine-year-old children. 


\section{METHODS}

\section{PARTICIPANTS}

The sample consisted of 40 participants (20 girls and 20 boys). They were elementary school students (age 9), with body height $140.46 \pm 5.72 \mathrm{~cm}$, body weight 37.84 $\pm 8.21 \mathrm{~cm}$, and body mass index $19.09 \pm 3.56$. The testing was performed in the physical education hall, in agreement with the school's teachers and principals. Respondents, their parents, and teachers were informed about the purpose of the research. They signed the consent to participate in the study, following the Helsinki Declaration on the Child's Rights. All testing was performed in November 2019. The Ethics Committee approved the Faculty of Sports and Physical Education study in Niš (Number 04-2115).

\section{PROCEDURES}

The body composition assessment variables were body height, body weight, body mass index (BMI), and body fat percentage (body fat \%). Measurements were made with a scale for determining body composition - bioelectrical impedance (BIA). It is a noninvasive and fast method for evaluating the body composition by emitting a low, safe dose of current that passes through the muscles without resistance. In contrast, some resistance exists when passing through fat (Omron BF511) (PRIBYL et al., 2011).

Test of Gross Motor Development - Second Edition (PALMER - BRIAN, 2016; VALENTINI, 2012A) was used to assess gross motor skills. According to Cools et al. (2009), the test can be used to identify children who are significantly behind their peers in gross motor performance. Also, plan programs to improve skills in those children showing delays and assess changes as a function of increasing age, experience, instruction, or intervention (COOLS et al., 2009). The Pearson test-retest reliability of the test showed a strong positive and significant correlation $(\mathrm{r}=.90, \mathrm{p}<.0001)$ for the TGMD-2 locomotor test $(\mathrm{r}=.83, \mathrm{p}<.001)$ and manipulative skills $(\mathrm{r}=.91, \mathrm{p}<.001)$ subtests (VALENTINI, 2012B).

To determine the subjects' level of coordination, an abbreviated BOT-2 test was applied (BRUININKS - BRUININKS, 2005), or subtest to assess motor coordination of the upper extremities (Subtest 7, Upper-Limb Coordination). Using the tasks of the applied test, the measurement of the subjects collected the data of the following variables: dropping and catching the ball with both hands, catching the thrown ball at a proper distance by the meter with both hands, dropping and catching the ball with one hand, catching the thrown ball at a reasonable distance by the meter with one hand, dribbling with one hand, dribbling with both hands, the precision of aiming and shooting the ball in the target and overall coordination of the upper extremities of the subjects.

The BOT-2 test subtest "Running speed and agility BOT-2 test" was applied to assess speed and agility for children's motor performance, which includes the following 
tests: Shuttle Run, Crossing the barrier laterally, Jumping on one leg, Side jumps on one leg, and Side jumps with both feet.

Physical Activity Level was determined using the questionnaire to assess the level of physical activity PAQ-C (VIDAKOVIĆ SAMARŽIJA - MIŠIGOJ DURAKOVIĆ, 2013). The questionnaire is easy to use and contains short, unambiguous questions to classify respondents (score 1 to 2 - not sufficiently physically active, 3 - moderately physically active, and 4 to 5 - very physically active) according to the given criterion, and consists of nine questions evaluated explicitly on a scale of 5 degrees. The overall result of physical activity is predicted based on the arithmetic mean of the answers given, separately assessed on a scale from 1 to 5. Study of Vidaković Samaržija - Mišigoj-Duraković (2013) showed high reliability, which was 0.81 , standardized alpha was 0.78 , and the average correlation between the particles was $r=0.17$. The results indicate the high reliability of this method of testing the level of physical activity in children.

For research, in cooperation with the teacher of physical education, in the elementary school, the following optimal testing conditions are provided: testing was performed on the morning shift, during the physical education class; the hall is preprepared, well lit, with a temperature of $20-22^{\circ} \mathrm{C}$ and participants were in physical education equipment and sneakers. Physical activity questionnaires were completed in the class.

The test was explained and demonstrated. Before the trial began, the participants warmed up for 10 minutes under the guidance of professors, coaches, and volunteers. They were tested under the same conditions and reported to be measured and tested in the same order. Measurement and testing were assisted by trained volunteers who were thoroughly familiar with the protocol before measuring and testing.

\section{STATISTICAL ANALYSIS}

Data processing was performed using the statistical program SPSS version 20.0. The level of significance is set at $\mathrm{p}<0.05$. Descriptive statistics (Mean \pm standard deviation) were calculated for all variables. An independent samples t-test was used to compare groups according to physical activity level, and to explore interactions with gender and BMI, and variables of motor performance, we used a 2 (physical activity level) x 2 (gender) x 2 (BMI group) MANOVA. F-values, p-values, and partial eta squared $\left(\eta^{2}\right)$ values were reported as MANOVA outcomes (GENTIER et al., 2013).

\section{RESULTS}

The average body height and weight of the physically inactive participants $(n=20)$ were $140.85 \pm 5.61 \mathrm{~cm}$ high and $39.06 \pm 8.15 \mathrm{~kg}$.

The average body mass index (BMI) score is $19.64 \pm 3.60$, which is within the standard body mass criterion. The mean value of their physical activity level is $2.62 \pm .53$, which indicates a low level of physical activity. Physically active children $(n=20)$ were an 
average of $139.60 \pm 6.32 \mathrm{~cm}$ high and $37.22 \pm 7.25 \mathrm{~kg}$ body weight. The average body mass index (BMI) score is $19.01 \pm 2.78$, within the normal body mass criterion. Also, the standard deviation values indicate that the variability of the results is not significant. Kolmogorov-Smirnov test values (KS) indicating the normality of the distribution of the analyzed variables.

There are statistically significant differences in Upper-limb coordination $(\mathrm{p}=.04)$ and Locomotor skills ( $\mathrm{p}=.03$ ). The mean result of the Test of Gross Motor Development was $79.87 \pm 7.96$, but there is a statistically significant difference between inactive and active children ( $\mathrm{p}=.029),(77.60 \pm 8.44$, and $82.70 \pm 5.41$, respectively) (Table 1$)$.

Table 1: Descriptive statistic

\begin{tabular}{|c|c|c|c|c|c|c|}
\hline Variable & PAL & $\mathrm{N}$ & Mean & SD & Std. Error 1 & (2-tailed) \\
\hline \multirow{2}{*}{ Height } & Act & 20 & 140.85 & 5.61 & 1.26 & \multirow{2}{*}{.513} \\
\hline & NonAct & 20 & 139.60 & 6.33 & 1.42 & \\
\hline \multirow{2}{*}{ Weight } & Act & 20 & 39.06 & 8.15 & 1.82 & \multirow{2}{*}{.455} \\
\hline & NonAct & 20 & 37.23 & 7.25 & 1.62 & \\
\hline \multirow{2}{*}{ BMI } & Act & 20 & 19.64 & 3.60 & .81 & \multirow{2}{*}{.536} \\
\hline & NonAct & 20 & 19.01 & 2.78 & .62 & \\
\hline \multirow{2}{*}{ Body Fat } & Act & 20 & 24.29 & 8.79 & 1.97 & \multirow{2}{*}{.741} \\
\hline & NonAct & 20 & 23.41 & 7.89 & 1.77 & \\
\hline \multirow{2}{*}{ Body Mass } & Act & 20 & 1243.95 & 106.27 & 23.76 & \multirow{2}{*}{.694} \\
\hline & NonAct & 20 & 1231.20 & 96.84 & 21.66 & \\
\hline \multirow{2}{*}{ Running speed and agility } & Act & 20 & 41.30 & 3.15 & .70 & \multirow{2}{*}{.086} \\
\hline & NonAct & 20 & 42.80 & 2.14 & .48 & \\
\hline \multirow{2}{*}{ Upper-limb coordination } & Act & 20 & 34.50 & 7.65 & 1.71 & \multirow{2}{*}{.041} \\
\hline & NonAct & 20 & 38.65 & 4.28 & .96 & \\
\hline \multirow{2}{*}{ Locomotor skills } & Act & 20 & 37.05 & 5.12 & 1.15 & \multirow{2}{*}{.037} \\
\hline & NonAct & 20 & 40.05 & 3.50 & .78 & \\
\hline \multirow{2}{*}{ Manipulative skills } & Act & 20 & 40.55 & 4.62 & 1.03 & \multirow{2}{*}{.099} \\
\hline & NonAct & 20 & 42.65 & 3.08 & .69 & \\
\hline \multirow{2}{*}{ TGMD2 } & Act & 20 & 77.60 & 8.44 & 1.89 & \multirow{2}{*}{.029} \\
\hline & NonAct & 20 & 82.70 & 5.41 & 1.21 & \\
\hline
\end{tabular}

The 2x2x2 MANOVA analysis indicated no significant interaction effect between gender, BMI and age group ( $p=0.089)$. Additionally, no significant interaction effects between gender and BMI group ( $\mathrm{p}=0.359)$, and gender and physical activity level $(\mathrm{p}=$ 0.137 ) occurred, and no main group effect for physical activity and BMI category $(\mathrm{p}=$ $0.176)$. 
Table 2: MANOVA

\begin{tabular}{|c|c|c|c|}
\hline Variable & F & sig. & $\begin{array}{c}\text { Partial Eta } \\
\text { Squared }\end{array}$ \\
\hline Gender & 1.618 & .188 & .224 \\
\hline BMI category & 2.053 & .102 & .268 \\
\hline PAL & 7.044 & .000 & .557 \\
\hline Gender*BMI category & 1.149 & .359 & .170 \\
\hline Gender*PAL & .886 & .503 & .137 \\
\hline PAL*BMI category & 1.192 & .338 & .176 \\
\hline $\begin{array}{c}\text { Gender*BMI } \\
\text { category*PAL }\end{array}$ & 2.149 & .089 & .277 \\
\hline
\end{tabular}

\section{DISCUSSION}

This research aimed to determine physical activity level, BMI, and gender differences in the motor performance of nine-year-old children. The results of this study showed that there are significant differences between physical activity level and locomotor skills, but not with manipulative skills. The sample of motor and physical activity assessment variables consisted of locomotor and manipulation skills tests, each with six motor tests for each area of knowledge. Locomotor skills that were performed were running, jumping in one leg, long jump. Manipulative skills were batting, running with the ball, catching and kicking, throwing overhead, and rolling the ball. The authors suggest that basic locomotor and manipulative motor skills are the primary mechanisms associated with participation in physical and health-related activities (LOGAN et al., 2011), similar to our study. Also, children with acceptable weight showed better motor competence than those who were overweight or obese, and weight status had a significant detrimental impact on gross motor skills and overall motor proficiency in children aged 6-8 years (MARMELEIRA et al., 2017).

There were statistically significant differences between inactive and active children, which confirm the results obtained. Robinson (2011) shows a moderate and significant correlation between perceived physical ability and basic motor skills in preschool children. The findings provide relevant information on children's motor development and indicate a positive relationship between preschoolers' self-perceptions of physical ability and basic motor skills (ROBINSON, 2011). The mean score on the Test of Gross Motor Development for the total sample of boys and girls of pre-school age was $29.33 \pm 10$, and $15.70 \pm 5.68$ for locomotor and $13.63 \pm 5.31$ for manipulative skills. These 
are lower values than the results of our sample, as expected for the age category, which was confirmed in previous studies (KHALAJ -AMRI, 2014). The total amount of physical activity and moderate-to-vigorous physical activity have typically correlated positively and sedentary lifestyle negatively with the level of gross motor skills in children (FISHER et al., 2005; WROTNIAK et al., 2006; WILLIAMS et al., 2008).

A study by Gentier (GENTIER et al., 2013) suggested that children's physical activity level affects fine and gross motor skills. Physical activity and movement experiences are important because it offers children the opportunity to develop adequate motor skill competence and the ability to maintain a physically active lifestyle (FISHER et al., 2005; GENTIER et al., 2013). The differences in performance of motor skills are attributed, among other factors, to different physical structures presented during life (VENETSANOU - ANTONIS, 2012). Some investigations have recently tried to verify the influence of these structural characteristics in the motor aspects within this context. Children's motor proficiency is negatively associated with body fat, and normal-weight children show better motor competence than those who are overweight or obese. The negative impact of excessive body weight is more substantial for gross motor skills that involve dynamic body movements than for stationary object control skills. Fine motor skills appear to be relatively independent of the constraints imposed by excessive body weight (MARMELEIRA et al., 2017).

Catenassi (2007) concluded that obese or overweight children have the same potential as normal children for developing gross motor skills and capable of performing movements with the same quality. Therefore, the differences in performance in children must be more related to physiological responses than with the organization of the training and motor development. Our study showed that differences might occur in physical activity level, but the small sample size makes it difficult to generalize these findings to the entire childhood population. Contrary to our research, boys had significantly faster running speed and agility, threw a ball at a target more successfully, had greater response speed, and scored lower in sorting shape cards than girls 8-10 years old (WROTNIAK et al., 2006). The research results bring attention to the importance of early stimulation of motor development and healthy lifestyles in children characterized by physical activity level. The optimal level of motor skills, well-developed fundamental motor skills, and healthy body structure is of great importance for children's cognitive, physical, and perceptual development. 
Vol 4, No 1 (2021): Stadium-Hungarian Journal of Sport Sciences

https://doi.org/10.36439/shjs/2021/1/9456

\section{REFERENCES}

Andriyani, F. D. (2014). Physical Activity Guidelines for Children. Jurnal Pendidikan Jasmani Indonesia, 10, (1).

Cameron, C. E., Cottone, E. A., Murrah, W. M., \& Grissmer, D. W. (2016). How Are Motor Skills Linked to Children's School Performance and Academic Achievement? Child Development Perspectives, 10, (2), 93-98.. http://doi.org/10.1111/cdep.12168

Catenassi, F. Z., Marques, I., Bastos, C. B., Basso, L., Ronque, E. R. V., \& Gerage, A. M. (2007). Relationship between body mass index and gross motor skill in four to sixyear-old children. Revista Brasileira de Medicina Do Esporte, 3, (4), 227-230. http://doi.org/10.1590/S1517-86922007000400003

Chen, W., Mason, S., Hammond-Bennett, A., \& Zalmout, S. (2016). Manipulative skill competency and health-related physical fitness in elementary school students. Journal of Sport and Health Science, 5, (4), 491-499. http://doi.org/10.1016/j.jshs.2015.03.007

Cools, W., Martelaer, K. De, Samaey, C., \& Andries, C. (2009). Movement skill assessment of typically developing pre-school children: a review of seven movement skill assessment tools. Journal of Sports Science \& Medicine, 8, (2), 154. http://doi.org/10.1016/S0031-9406(05)66164-0

Derri, V., Zissi, V., \& Pachta, M. (2001). Development of manipulative skills by children in primary grades. Journal of Human Movement Studies, 40, (5), 377-390.

Ericsson, I., \& Karlsson, M. K. (2014). Motor skills and school performance in children with daily physical education in school - a 9-year intervention study. Scandinavian Journal of Medicine and Science in Sports. http://doi.org/10.1111/j.16000838.2012.01458.x

Fisher, A., Reilly, J. J., Kelly, L. A., Montgomery, C., Williamson, A., Paton, J. Y., \& Grant, S. (2005). Fundamental movement skills and habitual physical activity in young children. Medicine and Science in Sports and Exercise, 37, (4), 684-688. http://doi.org/10.1249/01.MSS.0000159138.48107.7D

Floriani, V., \& Kennedy, C. (2008). Promotion of physical activity in children. Current opinion in pediatrics, 20, (1), 90-95. http://doi.org/10.1097/MOP.0b013e3282f3d9f9

Gallahue, D. L., \& Donnelly, F. C. (2003). Developmental physical education for all children. Revista de investigación clínica; organo del Hospital de Enfermedades de la Nutrición (Vol. 62). Retrieved from http://www.ncbi.nlm.nih.gov/pubmed/21416782

Gao, Y., Melin, M., Mäkäräinen, K., Rantalainen, T., Pesola, A. J., Laukkanen, A., ... Finni, T. (2018). Children's physical activity and sedentary time compared using assessments of accelerometry counts and muscle activity level. PeerJ, 6, e5437. http://doi.org/10.7717/peerj.5437

Gentier, I., D’Hondt, E., Shultz, S., Deforche, B., Augustijn, M., Hoorne, S., ... \& Lenoir, M. (2013). Fine and gross motor skills differ between healthy-weight and obese 
children. Research in developmental disabilities, 34, (11), 4043-4051. http://doi.org/10.1016/j.ridd.2013.08.040

Hills, A. P., Andersen, L. B., \& Byrne, N. M. (2011). Physical activity and obesity in children. British Journal of Sports Medicine, 45, (11), 866-870. http://doi.org/10.1136/bjsports-2011-090199

Khalaj, N., \& Amri, S. (2014). Mastery of gross motor skills in pre-school and early elementary school obese children. Early Child Development and Care, 184, (5), 795802. http://doi.org/10.1080/03004430.2013.820724

Landry, B. W., \& Driscoll, S. W. (2012). Physical activity in children and adolescents. PM and $R$. http://doi.org/10.1016/j.pmrj.2012.09.585

Logan, S. W., Morera, M., Daly, C. M., Robinson, L. E., Wadsworth, D. D., \& Rudisill, M. E. (2010). The comparison of two motor assessments in elementary school children. British Journal of Sports Medicine, 44, 81-2.

Lopes, V. P., Saraiva, L., \& Rodrigues, L. P. (2018). Reliability and construct validity of the test of gross motor development- 2 in Portuguese children. International Journal of Sport and Exercise Psychology, 16, (3), 250-260. http://doi.org/10.1080/1612197X.2016.1226923

Marmeleira, J., Veiga, G., Cansado, H., \& Raimundo, A. (2017). Relationship between motor proficiency and body composition in 6- to 10-year-old children. Journal of Paediatrics and Child Health, 53, (4), 348-353. http://doi.org/10.1111/jpc.13446

Palmer, K. K., \& Brian, A. (2016). Test of Gross Motor Development-2 Scores Differ Between Expert and Novice Coders. Journal of Motor Learning and Development, 4, (2), 142-151. http://doi.org/10.1123/jmld.2015-0035

Patki, K., Parasher, R. K., \& Bhatnagar, B. (2015). Relation between nutrition, socioeconomic status and fitness in elementary school children: a review of literature. Physiotherapy, 101, e1181-e1182. http://doi.org/10.1016/j.physio.2015.03.2104

Pribyl, M. I., Smith, J. D., \& Grimes, G. R. (2011). Accuracy of the Omron HBF-500 Body Composition Monitor in Male and Female College Students. International Journal of Exercise Science, 4, (2), 2.

Robinson, L. E. (2011). The relationship between perceived physical competence and fundamental motor skills in pre-school children. Child: care, health and development, 37, (4), 589-596.

Valentini, N. C. (2012a). Validity and reliability of the TGMD-2 for Brazilian children. Journal of Motor Behavior, 44, (4), 275-280. http://doi.org/10.1080/00222895.2012.700967

Venetsanou, F., \& Antonis, K. (2012). Motor performance differences in pre-school aged boys and girls. In Preschool Children: Physical Activity, Behavioral Assessment and Developmental Challenges, 19-37.

Vidaković Samaržija, D., \& Mišigoj-Duraković, M. (2013). Reliability of Croatian Version of the Questionnaire for Assessment of Overall Level of Physical Activity of Younger School Children. Hrvatski Športskomedicinski Vjesnik, 1, (28), 24-32. 
Wagner, M. O., Kipling Webster, E., \& Ulrich, D. A. (2017). Psychometric properties of the Test of Gross Motor Development, third edition: Results of a pilot study. Journal of Motor Learning and Development, 5, (1), 29-44. http://doi.org/10.1123/jmld.20160006

Wagner, M. O., Webster, E., \& Urich, D. A. (2015). Reliability and validity of the Test of Gross Motor Development 3 (German version). Journal of Sport \& Exercise Psychology, 37, S17.

Williams, H. G., \& Abernathy, D. (2004). Assessment of gross motor development. In The Psychoeducational Assessment of Preschool Children: Third Edition (pp. 204-233). http://doi.org/10.4324/9781410611451

Wrotniak, B. H., Epstein, L. H., Dorn, J. M., Jones, K. E., \& Kondilis, V. a. (2006). The relationship between motor proficiency and physical activity in children. Pediatrics, 118, (6), e1758-65. http://doi.org/10.1542/peds.2006-0742 